\title{
Las mujeres en el cine y TV movies españoles (2000-2012): representaciones, sujetos y contextos
}

\author{
Ma José GÁmez Fuentes \\ IUDESP-Universitat Jaume I de Castelló
}

\begin{abstract}
Resumen:
El presente artículo tiene como objetivo analizar la representación y participación de las mujeres en la producción fílmica española para cine y televisión atendiendo a: cómo se validan a través de los éxitos de las audiencias los esquemas de género heredados, cómo se vincula fílmicamente la experiencia de las mujeres en democracia con el imaginario construido a través de los relatos compartidos y de qué modo articula la industria la contribución de las mujeres.
\end{abstract}

Palabras clave: mujeres; género; cine español; TV movies; representación; audiencias.

\section{Women in Spanish film and TV movies (2000-2012): representations, subjects and contexts}

\begin{abstract}
:
This paper aims at analysing the representation and participation of women in Spanish films and TV movies according to the following parameters: how do audiences validate inherited gender roles through box office results, how do films relate women's experiences during democracy with social imaginaries constructed upon long shared narratives, how does the industry articulate women's contribution.
\end{abstract}

Key words: women; gender; Spanish cinema; TV movies; representation; audiences.

\section{Referencia normalizada:}

Gámez Fuentes, M. J. (2014): Las mujeres en el cine y TV movies españoles (2000-2012): representaciones, sujetos y contextos. Historia y Comunicación Social. Vol. 19. Núm. Especial Enero. Págs. 431-441.

Sumario: 1. Introducción. 1.1. Marcos, reconocimiento y sujetos. 1.2. Teoría feminista y medios. 2. Metodología. 3. Alicia a través de la taquilla. 3.1. Alicia, la taquilla y la industria. 4. Conclusiones.

\section{Introducción}

\subsection{Marcos, reconocimiento y sujetos}

Una de las principales líneas de investigación en el ámbito de las poliédricas relaciones entre la comunicación y la historia lo constituyen aquellos trabajos cuyo objetivo es desentrañar los marcos de inteligibilidad y legitimación que configuran diferentes artefactos culturales sobre las experiencias históricas de los sujetos. En ese 
sentido, el objetivo de nuestra propuesta reside en indagar, por un lado, qué vínculos podemos establecer entre las representaciones más consumidas y los contextos en los que se producen y, por otro, qué marcos de reconocimiento del sujeto político 'mujer' se articulan en dicho proceso. Para ello, examinaremos la producción fílmica para cine y televisión estrenada en España entre 2000 y 2012.

Nos gustaría, sin embargo, comenzar nuestra reflexión con una breve parada en una cinta de 1974: Alice doesn't live here anymore (Martin Scorsese). Alicia ya no vive aqui (en su traducción al castellano), la cual se convertiría en un icono feminista de independencia y empoderamiento al relatar la historia de una mujer que intenta romper con su limitada vida de ama de casa. Al año siguiente, el 29 de octubre, la National Organization for Women (NOW) en Estados Unidos organizó una huelga nacional contra la marginalización y discriminación de las mujeres utilizando en sus reivindicaciones, panfletos y pancartas el lema 'Alice doesn't'. A partir de ese momento, el 29 de octubre fue declarado por NOW como el 'Alice doesn't day'.

Años más tarde, en 1984, Teresa de Lauretis, referente en estudios cinematográficos feministas, publicó su seminal obra Alice Doesn't. Feminism, Semiotics and Cinema. En nuestro caso, inspiradas/os por la desgraciadamente sorprendente actualidad de los debates suscitados hace casi cuarenta años, pretendemos acercarnos a la producción filmica española para investigar dónde y de qué modo se encuentran representadas las particulares Alicias que conforman la imaginería de las mujeres españolas en las pantallas. ¿Dónde está la Alicia del cine y las TV movies españolas de mayor audiencia? ¿Está o no está? ¿Bajo qué marcos de reconocimiento?

\subsection{Teoría feminista y medios}

Para llevar a cabo nuestro estudio, nos basamos, como no podía ser de otro modo, en la tradición epistemológica que sustenta el estudio de la representación de las mujeres en la producción audiovisual, la cual se remonta a los años setenta cuando Laura Mulvey publica su célebre y controvertido artículo sobre el placer visual en el cine clásico (Mulvey, 1975). ${ }^{1}$ Aquí se empiezan a asentar las bases de una teoría visual feminista al apropiarse del psicoanálisis para explicar, por un lado, cómo el cine de Hollywood posiciona al espectador y a la espectadora respecto al placer visual y, por otro, cómo mediante tal posicionamiento se perpetúan las relaciones jerárquicas entre los sexos.

Fruto del debate originado por estos supuestos surgen en los ochenta numerosos estudios que, haciéndose eco de las influencias de los Estudios Culturales, van más allá de la aparente predeterminación de las posiciones espectatoriales desplegadas por los relatos. Conciben, así, a las audiencias femeninas como agentes negociadores de los productos que consumen y tienden a leer la relación de las mujeres (y de los sujetos en general) con la producción cultural en términos de "negociación". La principal aportación de estos estudios es que cuestionan el carácter unilateral y supuestamente preestablecido del proceso de consumo cultural y lo plantean como articulación de la materialidad en espacios de conflicto específicos. 
Es en este sentido en el que nos interesa acercarnos, en esta ocasión, a la relación de las mujeres y el cine español (Gámez Fuentes, 2004). Nuestro objetivo es indagar qué modelos identitarios inscritos en la memoria de España están siendo legitimados a través de su éxito con las audiencias. Para ello, analizaremos los marcos de reconocimiento (Butler, 1990) que legitiman los éxitos de taquilla de largometrajes estrenados durante nuestro período de estudio (2000-2012) y que tienen como protagonistas a las mujeres. Posteriormente pondremos dichos marcos en diálogo con aquellos procedentes de los éxitos de audiencias de TV movies (también protagonizadas por mujeres y estrenadas durante el mismo período) y con el lugar de las mujeres en la industria.

Nuestro trabajo contribuye así a una tradición académica que se inicia en España con la llegada de la democracia. En ese momento se comienzan a producir dentro de la academia española trabajos sobre los estereotipos de género en el lenguaje audiovisual (especialmente en la publicidad aunque también en otros corpus), sobre el sexismo en el lenguaje y sobre la construcción audiovisual de la subjetividad femenina. ${ }^{2}$ Algunos de estos trabajos incluyen ya entre sus líneas de reflexión consideraciones sobre la violencia inscrita a través del sexismo representacional pero no se vinculan con el debate socio-político sobre la violencia de género, creado a raíz de la implicación por parte de las instituciones y los agentes productivos a partir de finales de los noventa.

Indudablemente, esta producción académica se ha sustentado gracias a los diferentes Planes de Igualdad de Oportunidades y Planes Nacionales y Autonómicos de Investigación que han financiado iniciativas relacionadas con el género y la comunicación. Además, la legislación relativa a la violencia de género e igualdad desarrollada en España entre 2004 y 2007 ha conformado un marco jurídico que ha facilitado la entrada de la perspectiva de género en acciones y estudios y ha colocado a España como modelo para otros países (Gámez Fuentes y Nos Aldás, 2012). ${ }^{3}$ Por otro lado, la Ley General de Comunicación Audiovisual (LGCA) 7/2010 establece como susceptibles de sanción aquellos contenidos que fomenten odio, desprecio o discriminación por razones de raza, sexo, nacionalidad, etc., aunque el debate sobre la regulación de dichos contenidos es una cuestión todavía pendiente de abordaje (Belando Garín y Montiel Roig, 2011; Montiel Roig, 2009).

Tampoco está exenta de debate, y de ahí nuestro presente interés, la constante denuncia respecto al imaginario patriarcal que configuran las diferentes representaciones de las mujeres en la producción audiovisual española, a pesar de la tan celebrada emancipación de las mujeres en democracia. En este sentido, estudios como el de Arranz (2010) (centrado en el período que va de 2000 a 2006) ponen de manifiesto, por ejemplo, el escaso acceso de las mujeres a la dirección y producción audiovisual en el ámbito del cine y denuncian las correlaciones entre imaginarios patriarcales y autoría masculina. Se entienden, por tanto, en este contexto el nacimiento de iniciativas asociacionistas como AMECO (Asociación Española de Mujeres Profesionales de los Medios de Comunicación) en 1994 y CIMA (Asociación de mujeres cineastas y de medios audiovisuales) en 2006. 
Así pues, estamos ante un panorama en el que conviven: leyes avanzadas en materia de igualdad y producción audiovisual frente a mecanismo regulatorios deficientes; representaciones sexistas en materia de género y escasez de referentes representacionales que configuren un lugar no reduccionista de las mujeres en democracia; y, por último (pero no menos importante), escasa representación y apoyo a las mujeres en la producción, dirección o redacciones. Veremos a través de nuestro análisis de los éxitos en taquilla cómo legitiman las audiencias este contexto y de qué modo su consumo configura una particular memoria cultural.

\section{Metodología}

Para llevar a cabo nuestro análisis hemos trabajado inicialmente sobre dos muestras de películas. En primer lugar, hemos seleccionado las veinte películas españolas más taquilleras de cada uno de los últimos trece años según datos obtenidos del Boletín Informativo del ICAA (Instituto de la Cinematografía y de las Artes Audiovisuales) y los anuarios de la SGAE (Sociedad General de Autores y Editores) disponibles en sus respectivas páginas de internet. ${ }^{4}$ El período analizado, como ya adelantamos, va del 2000 al 2012, ambos inclusive. El criterio de selección de las películas ha sido que estuvieran protagonizadas por mujeres. Posteriormente, por cuestiones de espacio y en aras de homogeneizar la muestra de cine y televisión por éxitos de audiencia hemos acotado nuestro análisis a aquellas películas con más de un millón de espectadores/as (ya que todas las TV movies seleccionadas sobrepasan esa cantidad). En cuanto a las TV movies estrenadas durante ese mismo período el criterio utilizado ha sido también que estuvieran protagonizadas por mujeres, aunque en este caso la taquilla no ha funcionado como criterio excluyente ya que todas tenían más de un millón de espectadores/as.

Las variables que hemos investigado son qué roles presentan las protagonistas femeninas delante de la cámara y qué marco de reconocimiento (Butler, 1990) configuran respecto al sujeto político mujer en democracia y al legado de la dictadura. Finalmente hemos puesto en relación nuestras reflexiones con una mirada a la posición de las mujeres detrás de las cámaras.

Antes de avanzar, hemos de hacer algunas aclaraciones sobre los criterios de selección de películas. Por un lado, hemos obviado aquellos largometrajes donde la calificación de español respondía meramente a un componente de producción que no aparecía reflejado ni en la ambientación, ni en la dirección ni en el protagonismo de los/as actores u actrices. Por otro lado, en nuestro análisis no hemos duplicado la contabilidad de películas de cine en las ocasiones en que una misma película ocupara puestos en las taquillas de dos años consecutivos. En ese caso la hemos contabilizado una sola vez pero sumando ambas taquillas.

En cuanto a definir hasta qué punto un personaje femenino protagoniza una trama narrativa hemos considerado que una obra está protagonizada por un personaje feme- 
nino cuando este es el motor de la narrativa. Así, hemos elegido aquellas películas en que la historia se mueve primordialmente por las acciones, deseos o circunstancias procedentes del personaje o personajes femeninos, incluso si estos adoptan posiciones aparentemente tradicionales como esposa, novia o amante y, por tanto, tienen en ocasiones una pareja masculina. La diferencia con respecto a las películas en que pudieran hacer de co-protagonistas es que en este caso los personajes femeninos son el motor de la historia y no simples contrapartes del personaje masculino.

\section{Alicia a través de la taquilla}

Una vez aclarados los criterios comenzamos centrándonos en el ámbito del cine. Del total de 260 películas españolas más taquilleras estrenadas en cine entre 2000 y 2012 hemos descartado nueve por ser la contribución española meramente nominativa en términos de producción, como hemos explicado más arriba. De las 251 restantes, solo un 22,3\% (56 películas) está protagonizada por una mujer.

Estos datos, como ya comentamos en Gámez Fuentes (2013), no resultan especialmente halagüeños ya que las oportunidades de protagonismo de las mujeres se circunscriben a menos de un cuarto de la producción total de largometrajes en un período que abarca trece años. No obstante, entonces pudimos ver que si contabilizábamos también las ocasiones en que las mujeres actuaban de co-protagonistas el porcentaje pasaba de $22,3 \%$ a $43 \%$. Sin embargo, como ya constatamos, la visibilización de las mujeres en roles co-protagonistas no garantizaba imágenes empoderadoras de estas. Más bien, el marco de reconocimiento (Butler, 1990) que configuraban el $100 \%$ de estas narrativas era la de un imaginario que dejaba en la memoria cultural imágenes de mujeres que asumían co-protagonismo en tanto que significaban respecto a la masculinidad y la heteronormatividad.

Ahora bien, ahora centraremos nuestra atención en aquellas cintas con una recaudación superior al millón de espectadores/as. Nos referimos a (por orden de taquilla): 
Figura 1. Largometrajes protagonizados por mujeres (2000-2012) de más de un millón de espectadores/as.

\begin{tabular}{|l||l||l|}
\hline \multicolumn{1}{|c|}{ TÍTULO } & ESPECTADORES/AS & AÑO \\
\hline Los otros & 6.203 .682 & 2001 \\
\hline Lo imposible & 5.914 .601 & 2012 \\
\hline El orfanato & 4.274 .355 & 2007 \\
\hline Agora & 3.318 .399 & 2009 \\
\hline Juana la loca & 2.049 .333 & $2001 / 02$ \\
\hline Volver & 1.903 .583 & 2006 \\
\hline El laberinto del fauno & 1.649 .645 & $2006 / 07$ \\
\hline La comunidad & 1.382 .216 & 2000 \\
\hline REC & 1.341 .951 & 2007 \\
\hline Princesas & 1.168 .446 & 2005 \\
\hline Los ojos de Julia & 1.088 .368 & 2010 \\
\hline Spanish movie & 1.072 .280 & 2009 \\
\hline Te doy mis ojos & 1.054 .828 & $2003 / 04$ \\
\hline
\end{tabular}

Fuente: elaboración propia a partir de datos procedentes del ICAA y la SGAE.

Si observamos la Figura 1, de las trece películas con más de un millón de espectadores/as, la mitad las protagoniza una madre o esposa y solo una está dirigida por una mujer (Icíar Bollaín en el caso de Te doy mis ojos). Sin embargo, si nos detenemos a analizar el marco en el que se desarrollan esos roles observaremos que en muchos de ellos las mujeres adquieren su protagonismo en su lucha e intento de lidiar precisamente con esas posiciones. Se pone así de manifiesto que la relación de las protagonistas con las funciones tradicionales que han de realizar como madres, esposas, novias, hijas, etc. dista mucho de ser cómoda. Nos referimos a películas tan taquilleras como Los otros, Juana la loca, Volver, El laberinto del fauno, Princesas y Te doy mis ojos.

Las mujeres se han de enfrentar en las narrativas a un entorno respecto al cual han de resolver su lugar e incluso su supervivencia. Y lo más interesante es que el marco en el que se mueven supone un riesgo para su subjetividad: en Ágora, Juana la loca y El laberinto del fauno, el peligro procede del contexto político; en Los otros, Lo imposible, El orfanato y Volver la amenaza se construye vinculada a la función materna (Gámez Fuentes, 2004); en La comunidad, REC, Princesas y Te doy mis ojos, el riesgo se inscribe en el entorno más cotidiano y a pesar de las aparentes libertades alcanzadas en democracia. Mención aparte merece Spanish movie ya que epitomiza, precisa e irónicamente, las dificultades de los personajes femeninos en las narrativas de más éxito.

Ahora bien, si hemos de realizar una valoración sobre el impacto de dichas representaciones sobre las audiencias y qué imaginario cultural configuran debemos de ponerlas en diálogo con las procedentes de las TV movies para explorar las intersec- 
ciones de las representaciones que gozan de mayor aceptación entre el público. En este aspecto nos hemos centrado en los telefilmes españoles del mismo período que están exclusivamente protagonizados por mujeres, a saber:

Figura 2. TV movies de producción nacional protagonizadas por mujeres (2000-2012).

\begin{tabular}{|c|c|c|c|}
\hline TITULO & $\begin{array}{l}\text { CADENA - } \\
\text { AÑo }\end{array}$ & $\begin{array}{c}\text { AUDIENCIA } \\
\text { (N" espectadores) }\end{array}$ & ARGUMENTO \\
\hline $\begin{array}{l}\text { Felipey } \\
\text { Letizia }\end{array}$ & T5-2010 & 4.660 .500 & $\begin{array}{l}\text { Periodista enamora a príncipe } \\
\text { heredero. }\end{array}$ \\
\hline La Duquesa & T5-2010 & 4.185 .500 & Vida de la Duquesa de Alba. \\
\hline $\begin{array}{l}\text { Un burkapor } \\
\text { amor }\end{array}$ & A3-2009 & 4.009 .500 & $\begin{array}{l}\text { Joven española se enamora de } \\
\text { afgano. }\end{array}$ \\
\hline El pacto & T5-2010 & 3.770 .500 & $\begin{array}{l}\text { Siete jóvenes pactan quedarse } \\
\text { embarazadas. }\end{array}$ \\
\hline Mi gitana & T5-2012 & 3.590 .666 & Vida de Isabel Pantoja. \\
\hline Marisol & A3-2009 & 3.423 .500 & Vida de Pepa Flores. \\
\hline Carmina & T5-2012 & 3.063 .000 & Vida de Carmina Ordóñez. \\
\hline $\begin{array}{l}\text { No estás sola } \\
\text { Sara }\end{array}$ & La $1-2009$ & 2.983 .000 & $\begin{array}{l}\text { Joven estudiante sufre malos } \\
\text { tratos. }\end{array}$ \\
\hline La Baronesa & T5-2011 & 2.918 .000 & Vida de Tita Cervera. \\
\hline Volver a verte & T5-2011 & 2.768 .000 & Vida de Rocío Dúrcal. \\
\hline $\begin{array}{l}\text { Clara } \\
\text { Campoamor }\end{array}$ & La 1-2011 & 2.634 .000 & Wida de primera diputada. \\
\hline $\begin{array}{l}\text { La princesa de } \\
\text { Éboli }\end{array}$ & A3-2010 & 2.628 .000 & Vida de Ana de Mendoza. \\
\hline Sofia & A3-2011 & 1.932 .500 & $\begin{array}{l}\text { Princesa ortodoxa se casa con } \\
\text { heredero de la corona } \\
\text { española. }\end{array}$ \\
\hline $\begin{array}{l}\text { Hoy quiero } \\
\text { confesar }\end{array}$ & A3-2011 & 1.734 .500 & Vida de Isabel Pantoja. \\
\hline
\end{tabular}

Fuente: elaboración propia.

En la Figura 2 es interesante apreciar, en primer lugar, que el 64\% de las producciones para televisión están basadas en mujeres que han protagonizado la prensa rosa: nueve de los catorce telefilmes tiene como protagonistas a personajes como Isabel Pantoja, la reina Sofía, la baronesa Thyssen o Rocío Durcal, entre otros. Embarazo, amor y malos tratos ocupan el $21 \%$ (tres de las catorce TV movies) del resto de temáticas y solo el 14\% muestran mujeres en facetas más allá de las estereotípicas: nos referimos a las que representan a Clara Campoamor y Ana de Mendoza (princesa de Éboli), las cuales son, por otro lado, las únicas TV movies dirigidas por mujeres (por Laura Mañá y Belén Macías, respectivamente).

En el caso de las protagonistas procedentes de la prensa rosa, las obras, lejos de mitificar dichas figuras (y contrariamente a lo que ocurría en la dictadura), desmontan el glamour que las pudiera haber rodeado mostrando los claroscuros de sus vidas personales y profesionales y, por ende, los claroscuros de la época. Se repite así una 
dinámica que también legitiman los éxitos en cine: las audiencias respaldan visiones desmitificadores de los roles tradicionales femeninos. Por otro lado, hemos de subrayar que resulta sintomático de las dificultades de las mujeres en democracia que el resto de TV movies aborden cuestiones de extrema actualidad en el actual panorama político como son los malos tratos, las relaciones entre parejas interculturales y los derechos reproductivos.

Si elaboramos, por último, un listado de las 20 películas y TV movies más taquilleras por millones de espectadores/as los resultados que obtenemos son los siguientes:

Figura 3. Los 20 largometrajes y TV movies más taquilleros (2000-2012).

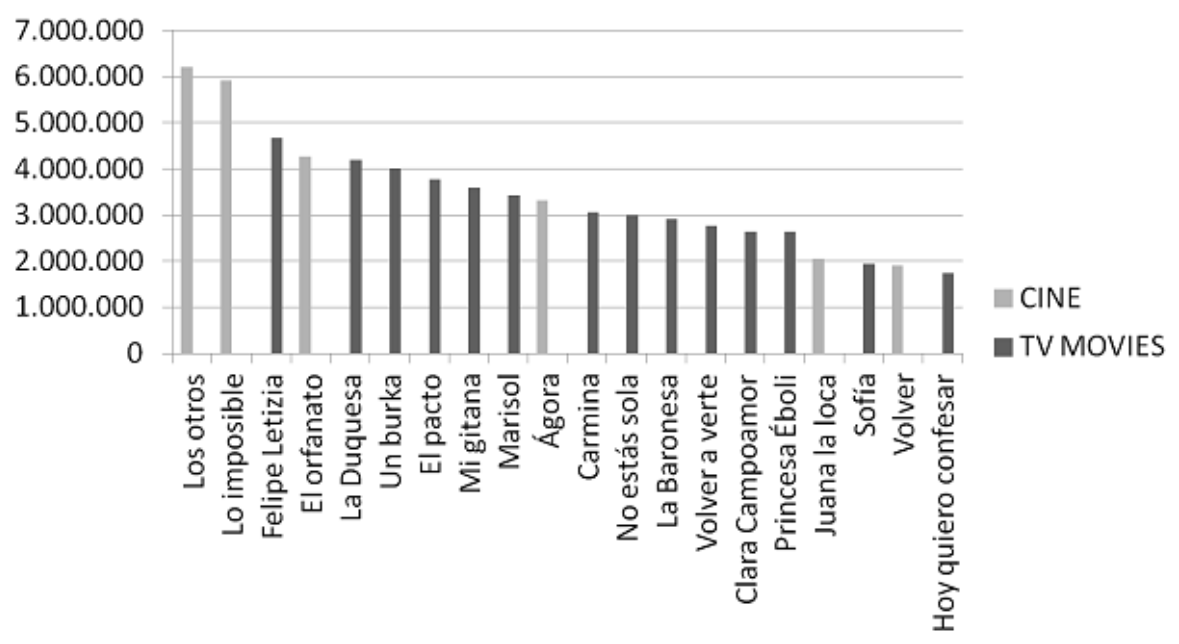

Fuente: elaboración propia.

Como podemos apreciar en la Figura 3, en los títulos con más audiencias de los últimos trece años protagonizados por mujeres, los modelos identitarios de mayor éxito proceden de la televisión, en concreto un $70 \%$ (catorce películas). Por otro lado, llama la atención que entre los títulos cinematográficos solo dos (Juana la loca y Volver) estén protagonizadas por actrices españolas y que la dirección femenina solo se da en televisión (quedando fuera el caso de Icíar Bollaín con Te doy mis ojos al no estar entre las veinte obras en conjunto más taquilleras). En cualquier caso, lo que resulta más significativo es que las audiencias respaldan mayoritariamente piezas que muestran personajes femeninos cuyo motor es negociar su identidad dentro de los patrones imperantes de cada momento.

\subsection{Alicia, la taquilla y la industria}

Así pues, aunque se podría pensar que la mayoría de personajes protagonistas femeninos reproducen los estereotipos de género ampliamente criticados por la literatura especializada, hemos podido observar que dichos roles conllevan matices interesantes si nos fijamos en los productos más populares entre el público. Hemos 
podido observar que lejos de reproducir los estereotipos imperantes los productos con mayores audiencias protagonizados por mujeres entre 2000 y 2012 ofrecen una visión no complaciente del lugar de las diferentes Alicias tanto en la dictadura como en la democracia.

Es cierto, sin embargo, como hemos visto, que la visibilidad de las mujeres directoras es casi nula. En el caso del cine solo encontramos a Iciar Bollaín y en el caso de la televisión a Laura Mañá y Belén Macías. Esto corrobora resultados de estudios anteriores (Arranz, 2010; Núñez Domínguez, 2010) que denuncian las dificultades de las mujeres en acceder a la dirección debido principalmente a estereotipos prejuiciosos sobre la capacidad de liderazgo o la falta de ambición de las mujeres. Esto conlleva que las productoras perciban un mayor riesgo a la hora de financiar a las mujeres y si no se es una directora de éxito consolidada la financiación se complique todavía más.

Por otro lado, si de marcos de reconocimiento hablamos, también hemos de considerar que incluso cuando las mujeres acceden a lugares detrás de las cámaras, la industria tiene ciertas dificultades en reconocer ese trabajo. De lo contrario no se explicarían los siguientes datos:

Figura 4. Porcentaje de largometrajes dirigidos por mujeres premiados en los Goya (20002012).

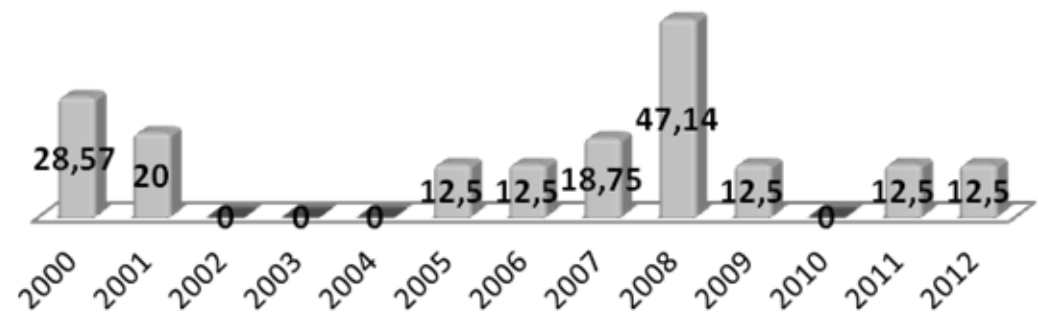

Fuente: elaboración propia.

Como podemos observar en la Figura 4, excepto en 2008 donde se recogen, en nuestra opinión, los frutos de una Ley de Igualdad aprobada en 2007 que pone el tema de las mujeres en primera línea de la agenda mediática del momento, en el resto de ediciones la desigualdad es manifiesta. Esto no son, obviamente, datos aislados. Desde 2000 a 2012 nuestro recorrido arroja otra serie de cifras: durante esos trece años solo en una ocasión una mujer recibe el Goya de Honor, solo dos reciben el Goya a la Mejor Dirección de Película, en el apartado de Dirección Novel también lo reciben solo dos, y 2,5 en Dirección de Documental. A lo largo de todo el período brillan por su ausencia en Mejor Dirección de Película de Animación, Mejor Dirección de Documental, Mejor Dirección de Película Extranjera de Habla Hispana y Mejor Dirección de Película Europea. 


\section{Conclusiones}

Llegados/as a este punto podemos concluir que las Alicias del panorama español, por lo menos las de delante de las cámaras de los mayores éxitos de audiencias, lejos de asumir los marcos hegemónicos los cuestionan y los enfrentan. Los mayores éxitos van acompañados de una lectura desmitificadora de las mujeres tanto de la dictadura como de la democracia Es por ello que, aunque acordamos completamente con las habituales críticas a la producción audiovisual sobre el sexismo de las imágenes imperantes, no podemos obviar que las audiencias, a través de su consumo, legitiman unos modelos identitarios que difícilmente se adaptan a los esquemas heredados. Más bien articulan sus posiciones respecto a estos como materialidad de subjetividades cruzadas por conflictos específicos, lo que impide consecuentemente cualquier lectura complaciente del pasado y del presente. Aunque queda mucho camino por recorrer en el ámbito del acceso de las mujeres a detrás de la cámaras y su reconocimiento por parte de la industria.

No querríamos concluir, empero, sin avanzar una futura línea de trabajo que consideramos que podría ser productiva. Nos referimos al éxito de las TV movies con protagonistas femeninas, especialmente en el caso de las protagonizadas por personajes de la prensa rosa. Este fenómeno es de especial interés y debería ser analizado en un futuro atendiendo a variables demográficas más allá del número de espectadores/ as.

\section{Bibliografía}

ARRANZ, F. (dir.) (2010). Cine y género en España. Una investigación empírica. Madrid: Cátedra.

BELANDO GARÍN, B.; MONTIEL ROIG, Gonzalo (coords.) (2011). Contenidos y mercado en la regulación de la Comunicación Audiovisual. El nuevo marco normativo de la Ley 7/2010 General de Comunicación Audiovisual. Valencia: Tirant lo Blanch.

BUTLER, J. (1990). Gender Trouble. London: Routledge.

DE LAURETIS, T. (1984). Alice Doesn't: Feminism, Semiotics, Cinema. Bloomington: Indiana University Press.

GÁMEZ FUENTES, M. J. (2003). "Género, representación y medios". En: Asparkía. Investigació Feminista, 14, Castellón: Universitat Jaume I, p. 59-70.

(2004). Cinematergrafía. La madre en el cine y la literatura de la democracia. Castellón: Ellago y Universitat Jaume I.

(2012). "Sobre los modos de visibilización mediático-política de la violencia de género en España: consideraciones críticas para su reformulación". En: OBETS. Revista de Ciencias Sociales, 2 (7), Alicante: Universidad de Alicante, p. 185-213. 
(2013). "La representación de las mujeres en el cine español: algunas reflexiones a partir de las audiencias de películas para cine y televisión (2000-2012)". Comunicando la cultura y ciencia recientes. Madrid: Vision Net [en prensa].

GÁMEZ FUENTES, M. J.; NOS ALDÁS, E. (2012). "Comunicación para la igualdad en el nuevo EEES: fundamentación crítica para el cambio social". En: Estudios sobre el mensaje periodístico, 18, Madrid: Universidad Complutense, p. 325-335.

MONTIEL ROIG, G. (2009). "¿Qué contenidos generan violencia y desigualdad de género? Una aproximación a la regulación y la autorregulación de los medios de comunicación". En: BERNARDO PANIAGUA, J. M. et al. (eds.). Retos de la comunicación ante la violencia de género. Marco jurídico, discurso mediático y compromiso social. Valencia: Tirant lo Blanch, p. 115-135.

MULVEY, L. (1975). "Visual Pleasure and Narrative Cinema". En: Screen, 16 (3), Oxford: Oxford University Press y University of Glasgow, p. 6-18.

NÚNEZ DOMÍNGUEZ, T. (2010). "Mujeres directoras de cine: un reto, una esperanza". En: Pixel-Bit. Revista de medios y educación, 37, Sevilla: Universidad de Sevilla, p. 121-133.

\section{Notas}

1 Para una ampliación sobre los fundamentos de la teoría fílmica feminista véase Gámez Fuentes (2003).

2 Para una ampliación de la tradición científica en España sobre este tema véase Gámez Fuentes (2012).

3 La llegada al gobierno del Partido Popular en noviembre de 2011 y la política de reducción del presupuesto dedicado a educación, investigación y servicios sociales ha supuesto un cambio drástico (léase negativo) en este ámbito.

4 Agradecemos a Laura Castillo su contribución en la fase preliminar de compilación de datos y elaboración de gráficos.

\section{La autora}

Profesora titular del departamento de Ciencias de la Comunicación de la Universitat Jaume I. Secretaria del Instituto de Desarrollo Social y Paz y miembra del Instituto Universitario de Estudios Feministas y de Género de dicha universidad. Especialista en género y medios de comunicación. Últimas publicaciones: "Re-framing the subject(s) of gender violence", en Peace Review (2013), "La vida secreta de las palabras: de mujeres, narrativas y violencia", en L'Atalante, Revista de Estudios Cinematográficos (2013) y "Sobre los modos de visibilización mediático-política de la violencia de género en España: consideraciones críticas para su reformulación", en OBETS. Revista de Ciencias Sociales (2012). 